\title{
Interleukin-15 enhances the proliferation, stimulatory phenotype, and antitumor effector functions of human gamma delta $T$ cells
}

Heleen H. Van Acker ${ }^{1 *}$, Sébastien Anguille ${ }^{1,2}$, Yannick Willemen ${ }^{1}$, Johan M. Van den Bergh ${ }^{1}$, Zwi N. Berneman ${ }^{1,2}$, Eva Lion ${ }^{1,2}$, Evelien L. Smits ${ }^{1,2,3+}$ and Viggo F. Van Tendeloo ${ }^{1+}$

\begin{abstract}
Background: Adoptive immunotherapy is gaining momentum to fight malignancies, whereby $\gamma \delta T$ cells have received recent attention as an alternative cell source as to natural killer cells and $a \beta T$ cells. The advent of $\gamma \delta T$ cells is largely due to their ability to recognize and target tumor cells using both innate characteristic and T cell receptor (TCR)-mediated mechanisms, their capacity to enhance the generation of antigen-specific T cell responses, and their potential to be used in an autologous or allogeneic setting.

Methods: In this study, we explored the beneficial effect of the immunostimulatory cytokine interleukin (IL)-15 on purified $\gamma \delta$ T cells and its use as a stimulatory signal in the ex vivo expansion of $\gamma \delta T$ cells for adoptive transfer. The expansion protocol was validated both with immune cells of healthy individuals and acute myeloid leukemia patients.

Results: We report that the addition of IL-15 to $\gamma \delta$ T cell cultures results in a more activated phenotype, a higher proliferative capacity, a more pronounced T helper 1 polarization, and an increased cytotoxic capacity of $\gamma \delta$ T cells. Moreover $\gamma \delta$ T cell expansion starting with peripheral blood mononuclear cells from healthy individuals and acute myeloid leukemia patients is boosted in the presence of $\mathrm{IL}-15$, whereby the antitumor properties of the $\gamma \delta \mathrm{T}$ cells are strengthened as well.
\end{abstract}

Conclusions: Our results support the rationale to explore the use of IL-15 in clinical adoptive therapy protocols exploiting $\gamma \delta T$ cells.

Keywords: Adoptive transfer, Expansion protocol, Gamma delta T cells, Interleukin-15, Leukemia

\section{Background}

Cellular immunotherapy for cancer is a rapidly evolving field, endeavoring to deal with common relapse or resistance to conventional treatments. Herewith, most interesting are the $\gamma \delta \mathrm{T}$ cells, a T cell subset possessing a combination of innate and adaptive immune cell traits [1]. Activated $\gamma \delta \mathrm{T}$ cells have strong cytotoxic effector

\footnotetext{
* Correspondence: heleen.vanacker@uantwerp.be

${ }^{\dagger}$ Equal contributors

'Laboratory of Experimental Hematology, Tumor Immunology Group (TIGR), Vaccine and Infectious Disease Institute (VAXINFECTIO), Faculty of Medicine and Health Sciences, University of Antwerp, Wilrijkstraat 10, 2650 Edegem, Antwerp, Belgium

Full list of author information is available at the end of the article
}

functions, by means of both death receptor/ligand and cytolytic granule pathways. Moreover, they have an immunoregulatory function, producing various cytokines, including the $\mathrm{T}$ helper (Th)1-associated cytokines tumor necrosis factor (TNF)- $\alpha$ and interferon (IFN) $-\gamma[1] . \gamma \delta \mathrm{T}$ cells are considered to be important players in cancer immune surveillance evidenced by; (a) the increased incidence of tumors in $\gamma \delta$ T cell deficient mice $[2,3]$, (b) the overrepresentation of $\gamma \delta$ T cells in reactive lymphatic regions associated with neoplasia, including acute myeloid leukemia (AML) [4], (c) their infiltration into solid tumors [5], and (d) their potential to kill a variety of tumor cells [1]. Pointedly, tumor-infiltrating $\gamma \delta \mathrm{T}$ cells 
recently emerged as the most significant favorable prognostic immune population across 39 malignancies [6]. As $\gamma \delta \mathrm{T}$ cells can kill tumor cells without previous contact and do not induce graft-versus-host disease, the adoptive transfer of $\gamma \delta$ T cells could be a promising alternative for stem cell transplantation and adoptive transfer of $\alpha \beta$ T cells [7].

Among the various tumor targets of $\gamma \delta$ T cells [8], we focused on AML, a heterogeneous hematological malignancy involving the clonal expansion of myeloid blasts in the bone marrow and peripheral blood. Although significant improvement in treatment of AML has been made, the unfortunate reality is that currently available treatments are largely ineffective for most AML patients $[9,10]$. In pursuit of new treatment options, several lines of evidence suggest that immunotherapy is an active modality in AML [11]. This includes the graft-versusleukemia effect associated with allogeneic hematopoietic stem cell transplantation (HSCT), where it has been demonstrated that elevated $\gamma \delta \mathrm{T}$ cell immune recovery after HSCT is associated with a better outcome in terms of infections, graft-versus-host disease and overall survival [12-14]. Moreover, while the use of HSCT is restricted to a minority of patients due to, among other, its high transplant-related mortality and morbidity $[10,15]$, $\gamma \delta \mathrm{T}$ cell immune therapy is well-tolerated and safe $[7,16]$. Adoptive transfer of $\gamma \delta \mathrm{T}$ cells is therefore an interesting alternative to tackle minimal residual disease and the high relapse rate in AML patients, optionally in combination with HSCT [17] or other (new) therapeutic agents [18-20]. Overall, while $\gamma \delta \mathrm{T}$ cell therapy holds great promise, clinical results are thus far modest, underscoring the need to further enhance the immunogenicity of the $\gamma \delta \mathrm{T}$ cell product [21].

$\gamma \delta \mathrm{T}$ cells can be expanded, using combinations of cytokines and phosphoantigens (e.g., isopentenyl pyrophosphate (IPP)) or aminobisphosphonates (e.g., zoledronate) [22]. The inclusion of aminobisphosphonates relies on their inhibition of farnesyl pyrophosphate synthase, a key enzyme of the mevalonate pathway, leading to accumulation of mevalonate metabolites such as IPP [23]. When peripheral blood mononuclear cells (PBMC) are treated with zoledronate, IPP will selectively accumulate in monocytes, due to the efficient drug uptake by these cells [24]. Therefore, in the absence of monocytes, addition of aminobisphosphonates is inefficient for induction of $\gamma \delta$ T cell expansion, and the use of IPP or related phosphoantigen is required. To date, the standard protocol for the expansion of $\gamma \delta$ T cells out of PBMC relies on the combination of zoledronate and interleukin (IL)-2 [25].

Limitations on the use of IL-2, relating to among other its toxicity, invigorate the investment in exploring other cytokines of the IL-2 family (also called the common $\gamma$ chain cytokine family; IL-4, IL-7, IL-9, IL-15, and IL-21) [26]. IL-15 is of interest as it is closely related to IL-2 and has got the top position in the US National Cancer Institute's ranking of 20 immunotherapeutic drugs with the greatest potential for broad usage in cancer therapy [27]. Moreover, both cytokines mediate their effects through a heterotrimeric receptor complex consisting of a cytokine specific $\alpha$-chain (IL-2R $\alpha$ or IL-15R $\alpha$ ), the IL$2 / 15 R \beta$-chain, and the common $\gamma$-chain [28]. IL-2 and IL-15 share many functions in regulating both adaptive (stimulation of $\mathrm{T}$ cell proliferation and induction of cytotoxic $\mathrm{T}$ lymphocytes) and innate (activating natural killer (NK) cells) immune responses [29]. In spite of the resemblances between both cytokines, they also have different functions in vivo. IL-15 is specifically known for its role in the maintenance of long-lasting, high-avidity $\mathrm{T}$ cell responses, whereas IL-2 may induce activationinduced cell death and provoke maintenance of regulatory $\mathrm{T}$ cells $[26,30]$. Therewithal, IL-15 has shown efficacy in murine models of malignancy, even when IL-2 failed [31, 32]. Clinical trials with IL-15 as monotherapy have recently been initiated, investigating its therapeutic potential. When looking at the lymphocyte subsets in blood, both $\gamma \delta \mathrm{T}$ cell proliferation and activation were observed after IL-15 administration.

These results stressed the need for a detailed characterization of the sheer effect of IL-15 on untouched and isolated $\gamma \delta$ T cells. The latter will be discussed in the first part of this paper, followed by the translation of the results into a $\gamma \delta$ T cell expansion protocol for adoptive transfer.

\section{Methods}

\section{Ethics statement and cell material}

This study was approved by the Ethics Committee of the Antwerp University Hospital (UZA; Edegem, Belgium) under the reference number B300201419756. Experiments were performed using buffy coats derived from healthy volunteer whole blood donations (supplied by the blood bank of the Red Cross, Mechelen, Belgium) and blood samples from patients with AML obtained from the hematological division of the UZA (Table 1). PBMC were isolated by Ficoll density gradient centrifugation (FicollPaque PLUS; GE Healthcare, Diegem, Belgium). Untouched $\gamma \delta$ T cells were isolated from PBMC using the EasySep $^{\text {Tx }}$ Human Gamma/Delta T Cell Isolation Kit (Grenoble, France), according to the manufacturer's instructions. The purity of the $\gamma \delta$ T cells was on average $94 \%$ (min-max; 89-98\%). Isolated $\gamma \delta$ T cells $\left(1 \times 10^{6}\right.$ cells $/ \mathrm{mL}$ ) were cultured for 5 days in Iscove's Modified Dulbecco's Medium (IMDM, Life Technologies, Merelbeke, Belgium), supplemented with $10 \%$ fetal bovine serum (FBS, Life Technologies), IPP (30 $\mathrm{g} / \mathrm{mL}$; tebu-bio, Le-Perray-en-Yvelines, France), and IL-2 (100 IU/mL; 
Table 1 AML patient characteristics

\begin{tabular}{|c|c|c|c|c|c|c|c|c|}
\hline$P$ & Sex & Age (years) & WHO type & Disease stage & PB blast $\%$ & BM blast $\%$ & Molecular & Cytogenetics \\
\hline A & $f$ & 51 & AML-nos & R1 & 6.5 & 16.2 & $\mathrm{WT}^{+}$ & $\mathrm{nl}$ \\
\hline B & $\mathrm{m}$ & 51 & AML-rga & Dx & 50 & 64.4 & $\mathrm{NPM}_{1}^{+}, \mathrm{WT}^{+}{ }^{+}$ & $\mathrm{nl}$ \\
\hline C & $\mathrm{m}$ & 62 & AML-nos & Dx & 2 & 72 & $\mathrm{ASXL}^{+}{ }^{+}$ & Trisomy 8 \\
\hline D & $\mathrm{m}$ & 61 & AML-nos & $\begin{array}{l}\text { Dx } \\
\text { CR1 }\end{array}$ & $\begin{array}{l}47.8 \\
0\end{array}$ & $\begin{array}{l}79.8 \\
0.6\end{array}$ & Negative & Deletion $17 p$ \\
\hline$E$ & $f$ & 76 & AML-mds & Evolution from MDS & 18 & ND & ND & ND \\
\hline $\mathrm{F}$ & $\mathrm{m}$ & 52 & AML-rga & Dx & 92.5 & 94.5 & $\mathrm{WT}_{1}^{+}, \mathrm{NPM}^{+}, \mathrm{FLT3}^{-\mathrm{ITD}^{+}}$ & $\operatorname{inv}(3)(q 21 q 26)$ \\
\hline G & f & 62 & AML-nos & CR1 & 0 & 0.8 & $\mathrm{ASXL1}^{+}$ & trisomy 8 \\
\hline
\end{tabular}

AML acute myeloid leukemia, $P$ Patient, $f$ female, $m$ male, WHO World Health Organization (WHO) 2008 classification for AML, $A M L-n o s$ AML not otherwise specified, $A M L$-rga AML with recurrent genetic abnormalities, $A M L$-mds AML with myelodysplasia (MDS)-related changes, $R 1$ first relapse of AML, $D x$ diagnosis stage, $C R 1$ first complete hematological remission of $A M L, P B$ blast \% percentage of AML blasts in peripheral blood, $B M$ blast \% percentage of AML blasts in bone marrow, ND no data, WT1 overexpression of Wilms' tumor 1 (WT1) gene transcript, NPM1 presence of mutated nucleophosmin 1 (NPM1), ASXL1 presence of mutation in additional sex combs 1 (ASXL1) gene, FLT3-ITD presence of internal tandem duplication of fms-like tyrosine kinase 3 (FLT3), $n /$ normal karyotype

Immunotools, Friesoythe, Germany) or IL-15 (12.5 ng/mL; Immunotools). The Burkitt's lymphoma tumor cell line Daudi was kindly provided to us by the laboratory of Prof. Kris Thielemans (Free University of Brussels, Brussels, Belgium), and the multiple myeloma cell line U266 was a gift from Prof. Wilfred Germeraad (Maastricht University Medical Center, Maastricht, the Netherlands).

\section{Proliferation assay}

To test the ability of IL-2 and IL-15, in combination with IPP, to induce $\gamma \delta$ T cell proliferation, a 5,6-carboxyfluorescein diacetate succinimidyl ester (CFSE; Invitrogen, Merelbeke, Belgium) flow cytometry-based proliferation assay was performed with isolated $\gamma \delta \mathrm{T}$ cells. Unstimulated CFSE-labeled $\gamma \delta \mathrm{T}$ cells served as negative control. After 5 days, cells were stained with LIVE/DEAD Fixable Aqua Stain (Life Technologies), CD56-PE (Becton Dickinson (BD); Erembodegem, Belgium), CD3-PerCP-Cy5.5 (BD), and $\gamma \delta$ T cell receptor (TCR)-APC (Miltenyi) and analyzed using a FACSAria II cytometer (BD). $\gamma \delta \mathrm{T}$ cell proliferation was assessed by quantifying the percentage of proliferating (CFSE-diluted) cells within the viable (LIVE/ $\left.\mathrm{DEAD}^{-}\right) \mathrm{CD}^{+} \gamma \delta \mathrm{TCR}^{+}$gate.

\section{Expansion protocol of $\gamma \delta \mathrm{T}$ cells (for adoptive transfer)}

PBMC were resuspended in Roswell Park Memorial Institute (RPMI) supplemented with $10 \%$ heatinactivated human $\mathrm{AB}$ serum (Invitrogen, Merelbeke, Belgium), zoledronate (5 $\mu \mathrm{M}$; Sigma-Aldrich, Diegem, Belgium), IL-2 (100 IU/mL), and/or IL-15 $(100 \mathrm{IU} / \mathrm{mL})$ at a final concentration of $1 \times 10^{6}$ cells/ $\mathrm{mL}$. Cell cultures were maintained at a cell density of $0.5-2 \times 10^{6}$ cells $/ \mathrm{mL}$ and were replenished every 2 to 3 days by adding IL-2/IL-15-supplemented medium. Phenotypic and functional assays were performed on cells harvested at least 14 days after first stimulations.

\section{Immunophenotyping}

Freshly isolated and 5-day proliferated $\gamma \delta \mathrm{T}$ cells were membrane-stained with the following monoclonal antibodies; $\gamma \delta$ TCR-FITC (Miltenyi), CD56-PE (BD), CD69PE (BD), and HLA-DR-PE (BD). Propidium iodide (PI; Life Technologies) was added to exclude dead cells from phenotypic analysis. Data acquisition was performed on a FACScan multiparametric flow cytometer (BD). Phenotypic characterization of $\gamma \delta \mathrm{T}$ cells was examined pre- and post-expansion, using CD27-FITC (BD), CD69FITC (BD), CD56-PE (BD), CD80-PE (BD), CD45RAPE-Cy7 (BD), CD28-PerCP-Cy5.5 (BD), CD16-PB (BD), CD86-V450 (BD), $\gamma \delta$ TCR-APC (Miltenyi), and HLADR-APC-H7 (BD). Live/Dead Fixable Aqua Stain was used to distinguish viable from non-viable cells. Data were acquired on a FACSAria II flow cytometer (BD). Corresponding species- and isotype-matched antibodies were used as controls.

\section{Cytokine production}

$\gamma \delta \mathrm{T}$ cell cultures were set up as described above. After 5 days of proliferation, cell-free supernatants were harvested and stored at $-20{ }^{\circ} \mathrm{C}$ before analysis. Samples were assessed by using enzyme-linked immunosorbent assay (ELISA) for the presence of TGF- $\beta$ (eBioscience, Vienna, Austria) and by using electrochemiluminescence immunoassay (ECLIA; Meso Scale Discovery (MSD), Rockville, MD, USA) for the presence of IFN- $\gamma$, TNF- $\alpha$, IL-5, IL-10, and IL-17. Cytokine measurements were also performed on supernatant of $\gamma \delta$ T cell cultures stimulated for an additional $4 \mathrm{~h}$ with the tumor cell lines Daudi and $\mathrm{U} 266$ at an effector-to-target (E:T) ratio of 5:1.

\section{Intracellular staining}

After 14 days of $\gamma \delta$ T cell expansion, IFN- $\gamma$ and TNF- $\alpha$ production was measured using a flow cytometric-based intracellular staining assay. Measurements were also performed after an additional hour of stimulation with 
Daudi or U266 cells (E:T ratio $=5: 1$ ). Brefeldin A (GolgiPlug $1 \mu \mathrm{L} / \mathrm{mL}$; BD) was added to the different conditions $\left(1 \times 10^{6}\right.$ cells $\left./ \mathrm{mL}\right)$ and incubated for $3 \mathrm{~h}$ at $37{ }^{\circ} \mathrm{C} / 5 \%$ $\mathrm{CO}_{2} . \gamma \delta \mathrm{T}$ cells were then washed and incubated with Live/Dead Fixable Aqua Stain, CD3-PerCP-Cy5.5 (BD) and $\gamma \delta$ TCR-APC (Miltenyi) for $30 \mathrm{~min}$ at $4{ }^{\circ} \mathrm{C}$. Subsequently, cells were fixed and permeabilized, using the Foxp3/Transcription Factor Staining Buffer Set (eBioscience), according to the manufacturer's instructions. Intracellular staining antibodies (IFN- $\gamma$-FITC and TNF- $\alpha-\mathrm{PE}-\mathrm{Cy} 7, \mathrm{BD})$ or the corresponding isotype control were added and allowed to bind for $1 \mathrm{~h}$ at $4{ }^{\circ} \mathrm{C}$.

\section{Cytotoxicity assay}

A flow cytometry-based lysis assay was performed in order to determine the killing activity of $\gamma \delta \mathrm{T}$ cells against the tumor cell lines Daudi and U266. Tumor cells were labeled prior to co-culture with PKH67 Green Fluorescent Cell Linker dye (Sigma-Aldrich), according to the manufacturer's protocol, and subsequently cocultured with $\gamma \delta$ T cells at different E:T ratios (1:10, 1:5, 1:1, 5:1, and 10:1). After $4 \mathrm{~h}$, cells were acquired on a FACSAria II flow cytometer following staining with annexin V-APC (BD) and PI. Killing was calculated based on the percentages of viable (annexin $\mathrm{V}^{-} / \mathrm{PI}^{-}$) cells within the $\mathrm{PKH}_{6} 7^{+}$tumor cell population using the following equation: $\%$ killing $=100-[(\%$ viable tumor cells with $\gamma \delta \mathrm{T}$ cells/\% viable tumor cells without $\gamma \delta \mathrm{T}$ cells $) \times 100]$.

\section{Statistics}

Flow cytometry data were analyzed using FlowJo (v10; Treestar, Ashland, OR, USA). GraphPad Prism software (v5.0; San Diego, CA, USA) was used for statistical calculations and artwork. Shapiro-Wilk normality test was performed to ascertain the distribution of the data. $p$ values $<0.05$ were considered statistically significant. All data are depicted as means \pm standard error of the mean.

\section{Results}

Enhanced $\gamma \delta \mathrm{T}$ cell proliferation in response to IL-15, concomitant with an activated phenotype

Stimulation of $\alpha \beta \mathrm{T}$ cell proliferation is a characteristic of both IL-2 and IL-15. To assess their effect on $\gamma \delta$ T cells, in combination with IPP, a 5-day proliferation assay was performed using isolated $\gamma \delta \mathrm{T}$ cells (Fig. 1). Unstimulated $\gamma \delta \mathrm{T}$ cells did not proliferate and were used as negative control. Although stimulatory effects were seen to some extent with the combination of IL-2+IPP, as evidenced by CFSE dilution, no statistical significance was reached relative to unstimulated $\gamma \delta$ T cells. In contrast, IL-15+IPP stimulation induced distinct $\gamma \delta \mathrm{T}$ cell proliferation (Fig. 1). This finding was confirmed by a higher absolute number of $\gamma \delta \mathrm{T}$ cells after 5-day culture with IL-15+IPP. Calculating mean fold expansion, being the number of $\gamma \delta$ T cells after stimulation divided by the number of $\gamma \delta$ T cells at the start, IL-2+IPP and IL-15 + IPP stimulation resulted in a mean fold expansion of $1.35 \pm 0.15 \times 10^{6}$ and $2.18 \pm 0.31 \times 10^{6} \gamma \delta$ T cells, respectively. Furthermore, exposure of human peripheral blood $\gamma \delta$ T cells to IL-15+IPP resulted in an improved activated phenotype. Surface expression of CD69 augmented from $1.63 \pm 0.52 \%$ (basal level) to $15.85 \pm 3.80 \%$ (IL-2+IPP) and $26.55 \pm 3.83 \%$ (IL-15+IPP), and HLA-DR expression went up from $12.16 \pm 2.36 \%$ (basal level) to $64.58 \pm 5.63 \%$ (IL-2+IPP) and $63.93 \pm 7.63 \%$ (IL-15+IPP). Notably, CD56 expression was significantly higher on IL-15+IPP stimulated $\gamma \delta \quad \mathrm{T}$ cells $(38.34 \pm 4.83 \%)$ than on
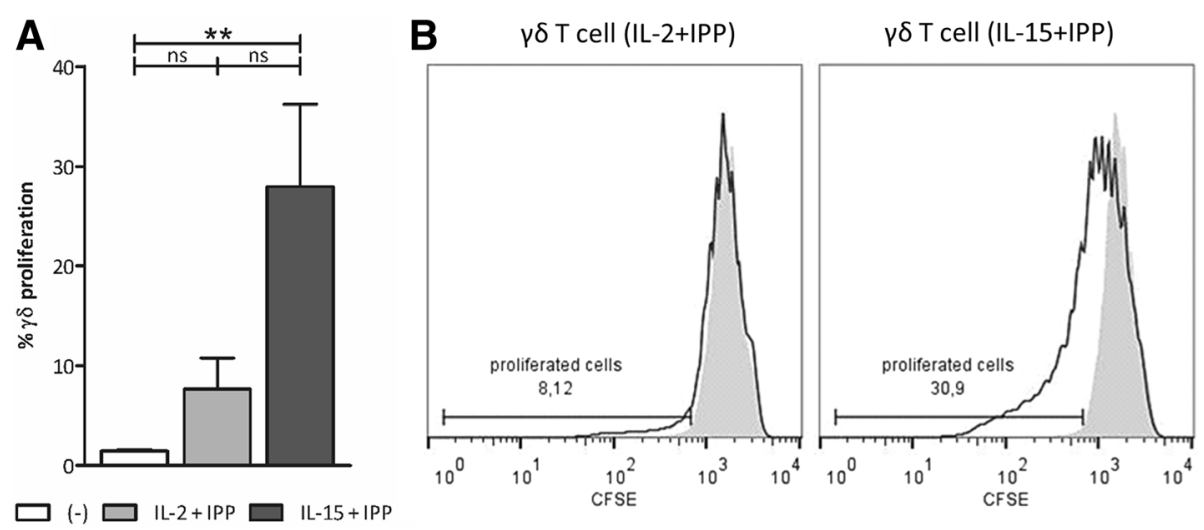

Fig. 1 Purified $\gamma \delta T$ cell stimulation with IL-15 and IPP for 5 days induces their proliferation. a Isolated $\gamma \delta$ T cells were stimulated with IL-2+IPP (gray bar) or IL-15+IPP (dark bar) for 5 days. Unstimulated $\gamma \delta$ T cells (white bar) were used as negative control. The percentage of proliferated (CFSE-diluted) cells within the viable $\gamma \delta T$ cell population was determined by flow cytometry $(n=5) \mathbf{b}$. Histogram overlays show CFSE dilution and gating of unstimulated $\gamma \delta$ T cells (gray-filled area) and $\gamma \delta$ T cells exposed to IL-2+IPP or IL-15+IPP (black line) for one representative donor. Friedman test with Dunn's multiple comparison test. ${ }^{* *} p<0.01$; ns not significant 
unstimulated $(19.20 \pm 4.49 \%)$ and on IL-2+IPP stimulated $\gamma \delta$ T cells $(28.14 \pm 4.73 \%)$.

\section{IL-15+IPP stimulated $\gamma \delta$ T cells display strong Th1 cytokine responses and are more effective killers than IL-2+IPP $\gamma \delta$ T cells}

An important question in the context of cancer immunotherapy is whether IL-15, as compared to IL-2, can boost $\gamma \delta \mathrm{T}$ cell effector functions, in terms of cytokine secretion and cytotoxic capacity. $\gamma \delta$ T cells stimulated with either IL-2+IPP or IL-15+IPP are characterized by a largely pro-inflammatory cytokine profile comprising IFN- $\gamma$ and TNF- $\alpha$. IFN- $\gamma$ levels were typically $>68 \mathrm{ng} /$ $\mathrm{mL} / 1 \times 10^{6} \gamma \delta \mathrm{T}$ cells. On average, $3512 \pm 2140$ and $4506 \pm 2527 \mathrm{pg} / \mathrm{mL} / 1 \times 10^{6} \gamma \delta \mathrm{T}$ cells of TNF- $\alpha$ was detected in supernatant of 5 -day cultures of IL-2+IPP and IL-15+IPP activated $\gamma \delta$ T cells, respectively. With the exception of the IL-5 concentration, for which a 4.4-fold higher concentration was produced by IL-2+IPP $\gamma \delta \mathrm{T}$ cells, no significant difference was found in the non Th1 cytokine secretion (IL-10, IL-17 and TGF- $\beta$ tested) between both $\gamma \delta \mathrm{T}$ cell types. After 5 days, $\gamma \delta \mathrm{T}$ cell cultures were harvested and exposed to Daudi or U266 tumor cells, to verify their antitumor activity, including cytokine secretion (Fig. 2a) and cytolytic capacity (Fig. 2b). The same trends were observed as prior to tumor cell exposure, i.e., a clear Th1 response for both IL-2 and IL-15-cultured $\gamma \delta$ T cells. However, IL-15+IPP $\gamma \delta \mathrm{T}$ cells gave rise to significantly higher concentrations of IFN- $\gamma$ compared to IL-2+IPP $\gamma \delta$ T cells, whereas the latter were more prone to a Th2 and Th17 response. As direct antitumor activity is a hallmark of $\gamma \delta$ T cells, and an important asset for immunotherapy, $\gamma \delta \mathrm{T}$ cellmediated cytotoxicity was tested next against Daudi and U266 cells. $\gamma \delta \mathrm{T}$ cell cytotoxicity augmented with increasing E:T ratios and $\gamma \delta \mathrm{T}$ cells from all donors were
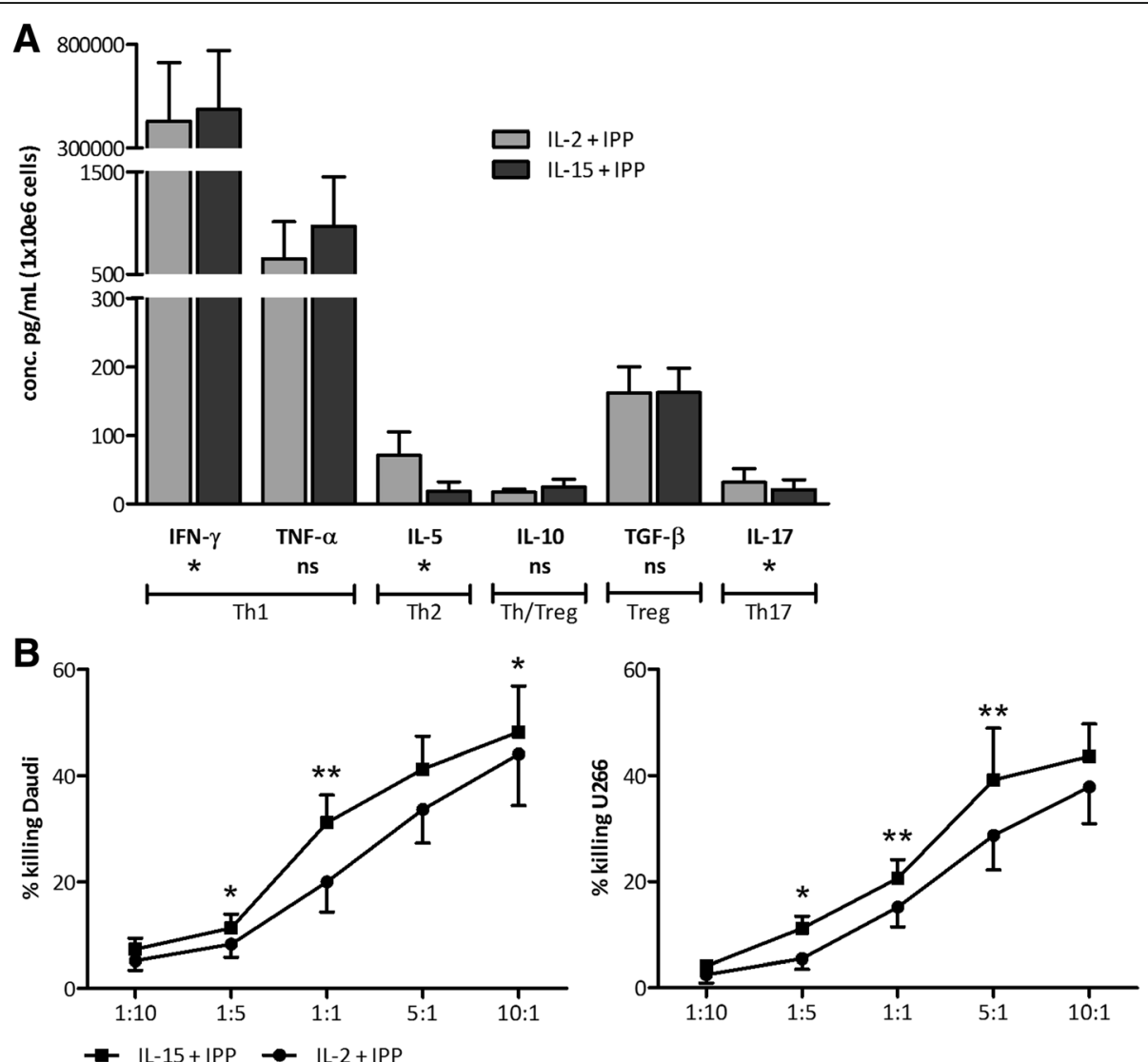

Fig. 2 Distinct Th1 cytokine release and marked tumor cell killing by IL-15+IPP activated $\gamma \delta$ T cells. a $\gamma \delta$ T cell invigorated for 5 days with IL-15 and IPP (dark bar) or IL-2 and IPP (gray bar) were stimulated for $4 \mathrm{~h}$ with U266 cells (E:T= 5:1). Bar graphs represent the cytokine secretion level of 1 million $\gamma \delta$ T cells $(\mathrm{pg} / \mathrm{mL})$, as determined by ECLIA (IFN- $\gamma$, TNF-a, IL-5, IL-10, and IL-17) and ELISA (TGF- $\beta$ ). Data are depicted as mean of duplicate measurements of six independent donors. Wilcoxon matched-pairs signed rank test. $\mathbf{b} \gamma \delta$ T cells stimulated for 5 days with IL-15+IPP (filled squares) or IL-2+IPP (filled circles) were analyzed by flow cytometry for cytotoxicity against the tumor cell lines Daudi and U266. Target cell killing was determined by annexin V/PI staining after 4-h incubation at different E:T ratios. Results are expressed as mean percentage killing, calculated using the formula specified in the "Methods" section. Data are from six different experiments involving 6-12 different donors. Paired $t$ test. ${ }^{* *} p<0.01 ;{ }^{*} p<0.05$ 
able to kill both tumor cell lines. In addition, $\gamma \delta$ T cellmediated lysis was unambiguously stronger for the IL-15 + IPP stimulated $\gamma \delta$ T cells in comparison with the IL-2 +IPP stimulated ones against both Daudi and U266 (Fig. 2b).

\section{IL-15 boosts IL-2/zoledronate-mediated expansion of $\gamma \delta \mathrm{T}$ cells}

As a first step in the clinical translation of the preceding results towards an improved protocol for the expansion of $\gamma \delta \mathrm{T}$ cells for adoptive transfer, expansion based on stimulation of PBMC with IL-2 and zoledronate was compared with responsiveness to IL-15 and zoledronate. Of the four healthy donors tested, only half of the cultures stimulated with IL-15 and zoledronate succeeded. One culture was considered to have failed due to a culture viability of less than $50 \%$ and another one due to the absence of $\gamma \delta \mathrm{T}$ cell expansion. Yet, IL-2+zoledronate-mediated $\gamma \delta \mathrm{T}$ cell expansion occurred in all four donors. On the other hand, when IL-15 was added as a third stimulus to the standard expansion protocol (IL2+zoledronate), a clear effect was detected (Fig. 3). Despite the fact that the percentage (Fig. 3b) and viability of $\gamma \delta$ T cells after 14 days were similar between cultures stimulated with IL-2+zoledronate or IL-2+IL-1 zoledronate, a significant increase in total $\gamma \delta$ T cell yield was observed when IL-15 was added to the cultures (Fig. 3a). On average, IL-2+zoledronate cultures showed a 590-fold increase in $\gamma \delta$ T cells after 14 days, whereas addition of IL15 almost led to a 1000 -fold increase. To ascertain the strength of the immune proliferative and stimulatory effect of IL-15, immune cells of AML patients (Table 1) were included. First, AML patients had a significantly lower proportion of $\gamma \delta \mathrm{T}$ cells in PBMC in comparison with healthy donors $(0.30 \pm 0.13$ versus $1.91 \pm 0.37 \%$, respectively; $p=0.0234$ ). Next, it should be noted that in contrast to the $100 \%$ success rate of $\gamma \delta \mathrm{T}$ cell expansion (defined as $\geq 70 \% \gamma \delta$ T cells after culture $[33,34]$ ) starting from PBMC of healthy donors, less than half of the $\gamma \delta \mathrm{T}$ cell expansion cultures from AML patients succeeded

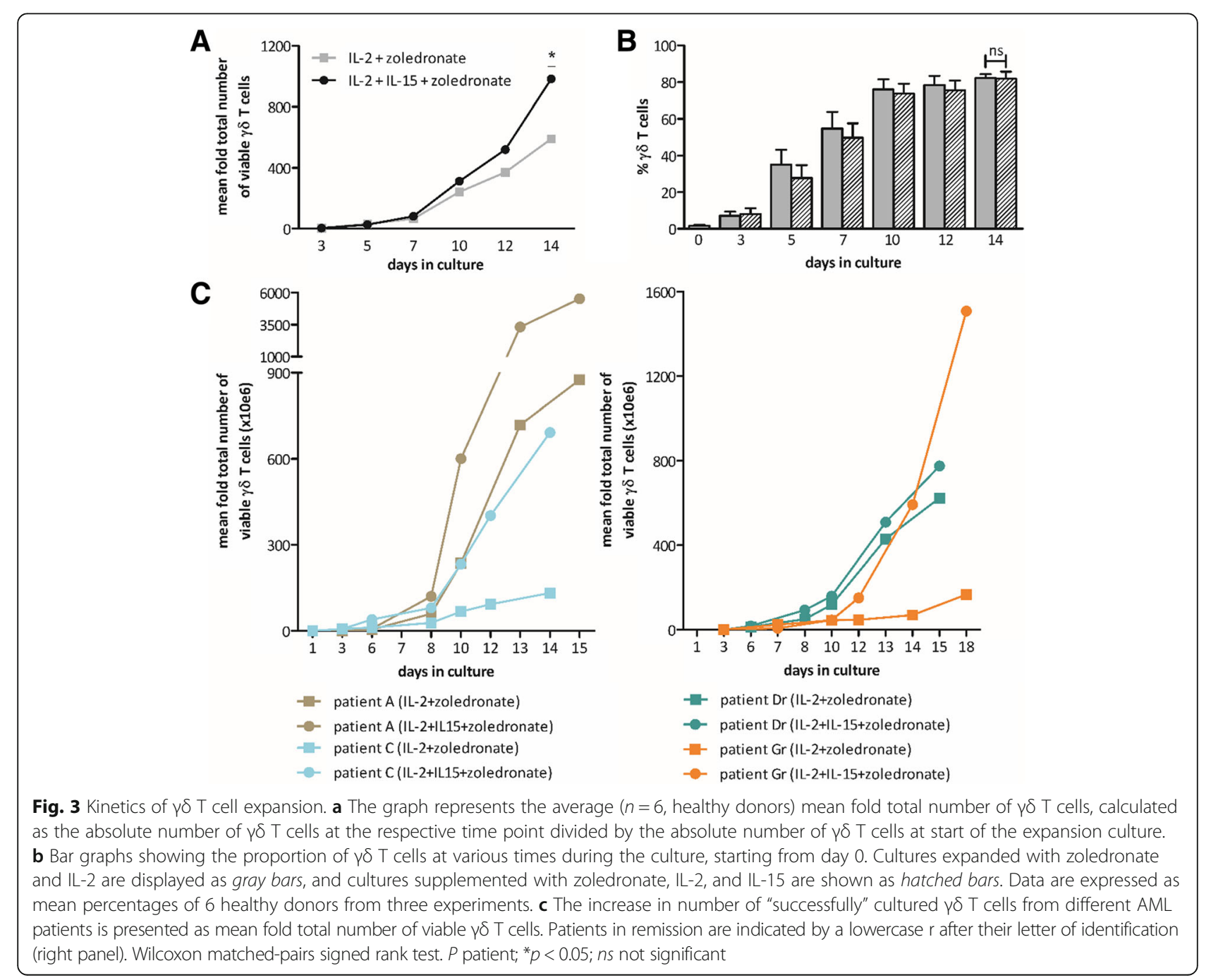


(Table 2). However, no direct correlation could be made between $\gamma \delta \mathrm{T}$ cell percentages in PBMC at start and the success of the expansion culture. Cultures that expanded relatively poorly, but in which nonetheless sufficient (viable) $\gamma \delta$ T cells were induced for (functional) testing, were also included. Importantly, similar to the healthy donors, $\gamma \delta$ T cells expansion was convincingly stronger for all AML patients when IL-15 was added to the cultures (Fig. 3c).

\section{Fourteen-day expansion using IL-2+IL-15+zoledronate gives rise to $\gamma \delta T$ cells with an activated memory phenotype}

At culture initiation (day 0) and termination (day 1415), we subjected the $\gamma \delta \mathrm{T}$ cell cultures to immunophenotyping. Whereas the four distinct effector/memory states were nearly evenly represented in terms of percentages by circulating $\gamma \delta$ T cells of healthy donors at day 0 , with a small preponderance for the naïve and central memory phenotype, the vast majority of expanded cells were effector memory $\gamma \delta \mathrm{T}$ cells and to a lesser extent central memory $\gamma \delta$ T cells (Fig. 4). $\gamma \delta$ T cells of AML patients, however, deviated from this pattern (Fig. 4). Likely, the stage of the disease, i.e., diagnosis, relapse or remission, plays a role in this phenomenon. For example, notwithstanding the rather small patient group, patients at diagnosis or in relapse displayed at day 0 a higher amount of central memory $\gamma \delta \mathrm{T}$ cells as compared to healthy donors, whereas remission patients strikingly had less central memory $\gamma \delta \mathrm{T}$ cells. Undoubtedly, patient-dependent factors also play a role, for instance when looking at the distribution of patient G (Fig. 4). Still, in analogy with healthy donors, expanded $\gamma \delta$ T cells of AML patients show a clear predominance for the memory stages (Fig. 4). Further phenotypic characterization revealed a marked increase in expression level of the activation associated markers CD56, CD69 and HLA-DR on expanded $\gamma \delta$ T cells of healthy donors, in combination with an increase in the co-

Table 2 Outcome of in vitro expansion of $\gamma \delta T$ cells from PBMC of AML patients

\begin{tabular}{|c|c|c|c|}
\hline P & 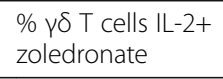 & 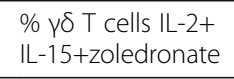 & Success \\
\hline A & 75.9 & 91.9 & Yes \\
\hline B & 16.8 & 12.4 & No \\
\hline C & 84.4 & 94.0 & Yes \\
\hline D & 17.2 & 46.6 & No \\
\hline Dr & 76.6 & 89.4 & Yes \\
\hline$E$ & 5.65 & 1.80 & No \\
\hline $\mathrm{F}$ & 4.31 & 1.84 & No \\
\hline $\mathrm{Gr}$ & 27.1 & 50.8 & No \\
\hline
\end{tabular}

$P$ patient, $\operatorname{Pr}$ patient in remission stimulatory molecules CD80 and CD86 (Fig. 5). Expansion, however, had no effect on the expression of CD16 and CD28. If we then looked at the phenotype of patient-derived $\gamma \delta \mathrm{T}$ cells after expansion, we perceive an increase in the early and late activation markers CD69 and HLA-DR as well (Fig. 5). Interestingly, $\gamma \delta \mathrm{T}$ cells of patients in remission express less HLA-DR (and CD69) after expansion in comparison to healthy controls and patients with acute disease. The activated phenotype of $\gamma \delta \mathrm{T}$ cells from remission patients is nonetheless clearly improved upon addition of IL-15. With regard to CD56 expression, all patient $\gamma \delta$ T cells exhibited already elevated levels at start, similar to those of healthy donors after expansion. After expansion, a down-regulation of CD56 is seen, which is more pronounced in patients in remission and $\gamma \delta \mathrm{T}$ cells expanded with IL-2+zoledronate. The same phenomenon holds true for CD16 upon expansion. Concerning the expression of CD80, a marked upregulation was detected after expansion, even more pronounced as compared to healthy donors. Whereas the expression of CD86 is similar for patient A, patient $\mathrm{C}$, and healthy donors, $\gamma \delta$ T cells of patients in remission expressed less of this co-stimulator after expansion (Fig. 5). In summary, expanded $\gamma \delta \mathrm{T}$ cells display an activated memory phenotype, based on the enhanced expression of CD69, HLA-DR, CD56, CD80, and CD86.

The frequency of IFN- $\gamma$-producing $\gamma \delta T$ cells is considerably higher after IL-2+IL-15+zoledronate expansion compared to IL-15-free expansion

To study the functionality of the expanded $\gamma \delta$ T cells, we first determined their Th1 polarization. In the absence of additional stimuli, the mean frequency of IFN- $\gamma$ producing $\gamma \delta \mathrm{T}$ cells after expansion was significantly higher when stimulated with IL-2+IL-15+zoledronate (3.28 $\pm 0.81 \%)$, as compared to IL-2+zoledronate (1.49 $\pm 0.43 \%$ ) (Fig. 6a). This more pronounced Th1 profile of $\gamma \delta \mathrm{T}$ cells, seen when IL-15 is present during expansion, also holds true upon addition of tumor cells to the cultures. When Daudi cells were added, we even observed an amplified IFN- $\gamma$ production as compared to the control (no tumor cells) condition (Fig. 6a). Despite having low numbers of TNF- $\alpha$-producing $\gamma \delta \mathrm{T}$ cells, generally below $1 \%$, the same trends were seen as with IFN- $\gamma$. Proceeding with immune cells of AML patients, different observations were seen as compared to expanded $\gamma \delta$ $\mathrm{T}$ cells of healthy donors (Fig. $6 \mathrm{~b}$ ). Whereas the fraction of $\gamma \delta$ T cells positive for IFN- $\gamma$ after stimulation with IL$2+$ IL-15+zoledronate was comparable between healthy donors and AML patients, IL-2+zoledronate stimulation gave rise to more IFN- $\gamma$ positive $\gamma \delta$ T cells when derived from AML patients relative to healthy donors. Moreover, the IL-2+zoledronate cultures of AML patients 

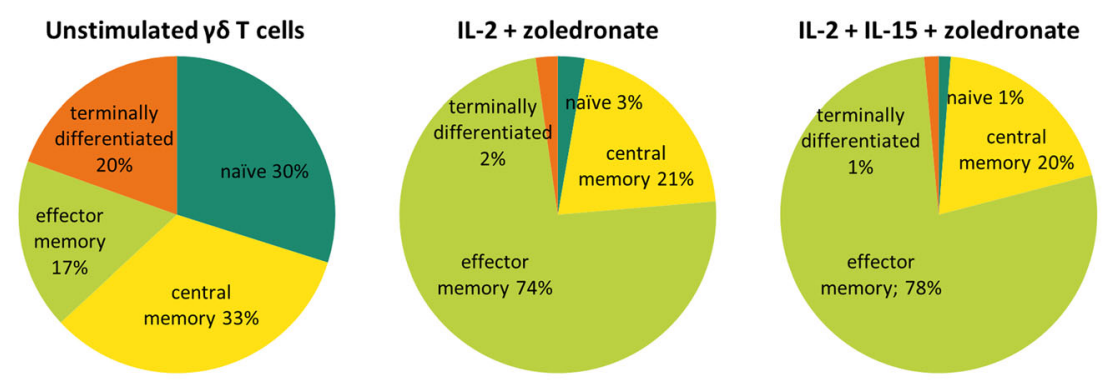

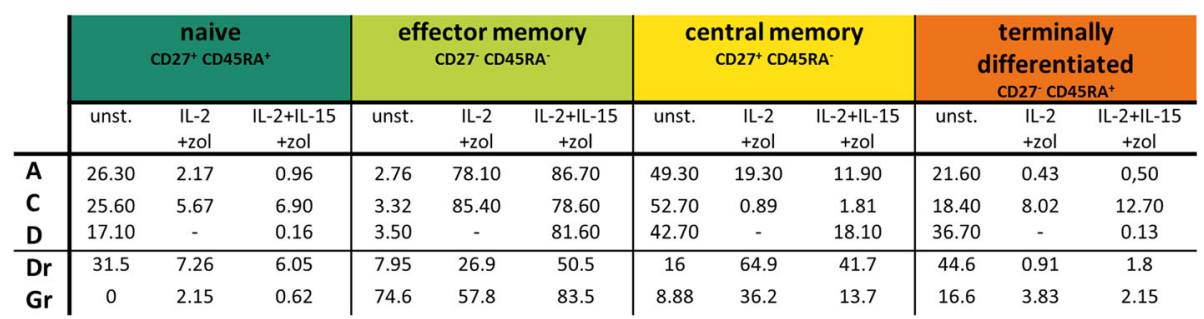

Fig. 4 Effector memory phenotype of $\gamma \delta T$ cells pre- and post-expansion. Average percentage of naïve $\left(C D 45 R A^{+} C D 27^{+}\right)$, effector memory (CD45RA ${ }^{-}$CD27 ${ }^{-}$), central memory $\left(C D 45 R^{-} C D 27^{+}\right)$and terminally differentiated $\left(C D 45 A^{+} C D 27^{-}\right) \gamma \delta T$ cells, before (unstimulated) and after expansion, represented as pie charts for six healthy donors. Values of $\gamma \delta T$ cells of patients are listed in the table below. - no value due to low cell number, Pr patient in remission, unst. unstimulated, zol zoledronate

performed equally well in terms of IFN- $\gamma$ production, if not better, than the IL-2+IL-15+zoledronate condition. Next, when tumor cells were added to expanded $\gamma \delta \mathrm{T}$ cells from patients, blunting of the $\gamma \delta$ T cell helper function could be observed to a certain degree pertaining to healthy donor expanded $\gamma \delta$ T cells. Here, $\gamma \delta$ T cells of patients with active disease did similar in terms of percentage IFN- $\gamma$ positive cells after expansion with or without IL-15. On the other hand, $\gamma \delta$ T cells of remission patient Dr, of which both protocols had yielded sufficient $\gamma \delta \mathrm{T}$ cells for functional testing, exhibited an almost doubling in the number of IFN- $\gamma$ positive cells when expanded in the presence of IL-15 and challenged with tumor cells.

\section{Addition of IL-15 to the expansion medium results in a significant increase in the $\gamma \delta \mathrm{T}$ cell-mediated cytotoxicity against tumor cells}

Finally, we determined the cytotoxic potential of the expanded $\gamma \delta$ T cells against the Daudi and U266 tumor cell lines (Fig. 6c). $\gamma \delta$ T cells of healthy donors displayed an increase in tumor cell killing upon increasing E:T ratios. Notably, addition of IL-15 in the expansion cultures evoked a superior cytotoxic capacity of expanded $\gamma \delta \mathrm{T}$ cells at the 10:1 ratio for both tumor cell lines. Similarly, the cytotoxic capacity of $\gamma \delta \mathrm{T}$ cells originating from AML patients was improved upon expansion in IL-15. However, in general, killing values of AML-derived $\gamma \delta \mathrm{T}$ cells were lower than those of healthy donor $\gamma \delta \mathrm{T}$ cells. At the 10:1 ratio, average killing of Daudi by expanded $\gamma \delta$ T cells was $27.26 \pm 10.86$ and $32.03 \pm 14.17 \%$, with respectively the IL-2+zoledronate $(n=3)$ and IL-2+15 +zoledronate $(n=5)$ expansion protocols. For U266 killing, percentages of $24.89 \pm 3.51$ and $35.19 \pm 4.96 \%$ were true. Finally, for some AML patients e.g., patient A, cytotoxic capacity is highly dependent on the target cell line (Fig. 6c).

\section{Discussion}

To date, adoptive immunotherapy using $\mathrm{T}$ lymphocytes has been applied for nearly 30 years [35]. Since then, vast improvements, including the use of chimeric antigen receptor (CAR) or $\mathrm{T}$ cell receptor (TCR) genemodified killer $\mathrm{T}$ cells, have been made. This resulting in proven clinical benefit for end-stage cancer patients for which standard therapy failed and the provision of longterm protection in some cases [36-38]. Notwithstanding this progress in the field, one of the major problems encountered with the adoptive transfer of classical $\alpha \beta \mathrm{T}$ cells, gene-modified or not, is the occurrence of off- and on-target toxicity [37]. Here, $\gamma \delta$ T cells have received recent attention as an alternative cell source for $\mathrm{T}$ cellmediated anticancer therapy [7]. Namely, both adoptive transfer and in vivo activation/expansion of $\gamma \delta \mathrm{T}$ cells are safe therapeutic modalities that can result in objective clinical responses in the treatment of cancer [7, 16]. A major advantage with using $\gamma \delta \mathrm{T}$ cells is that they are unlikely to cause graft-versus-host disease, allowing them to be generated from healthy donors and given in an allogeneic setting as an "off-the-shelf" therapeutic [7, 14]. In this study, we explored the beneficial effect of IL-15 on $\gamma \delta \mathrm{T}$ cells and its use as stimulatory signal in the ex vivo expansion of $\gamma \delta$ T cells for adoptive transfer. The strength 

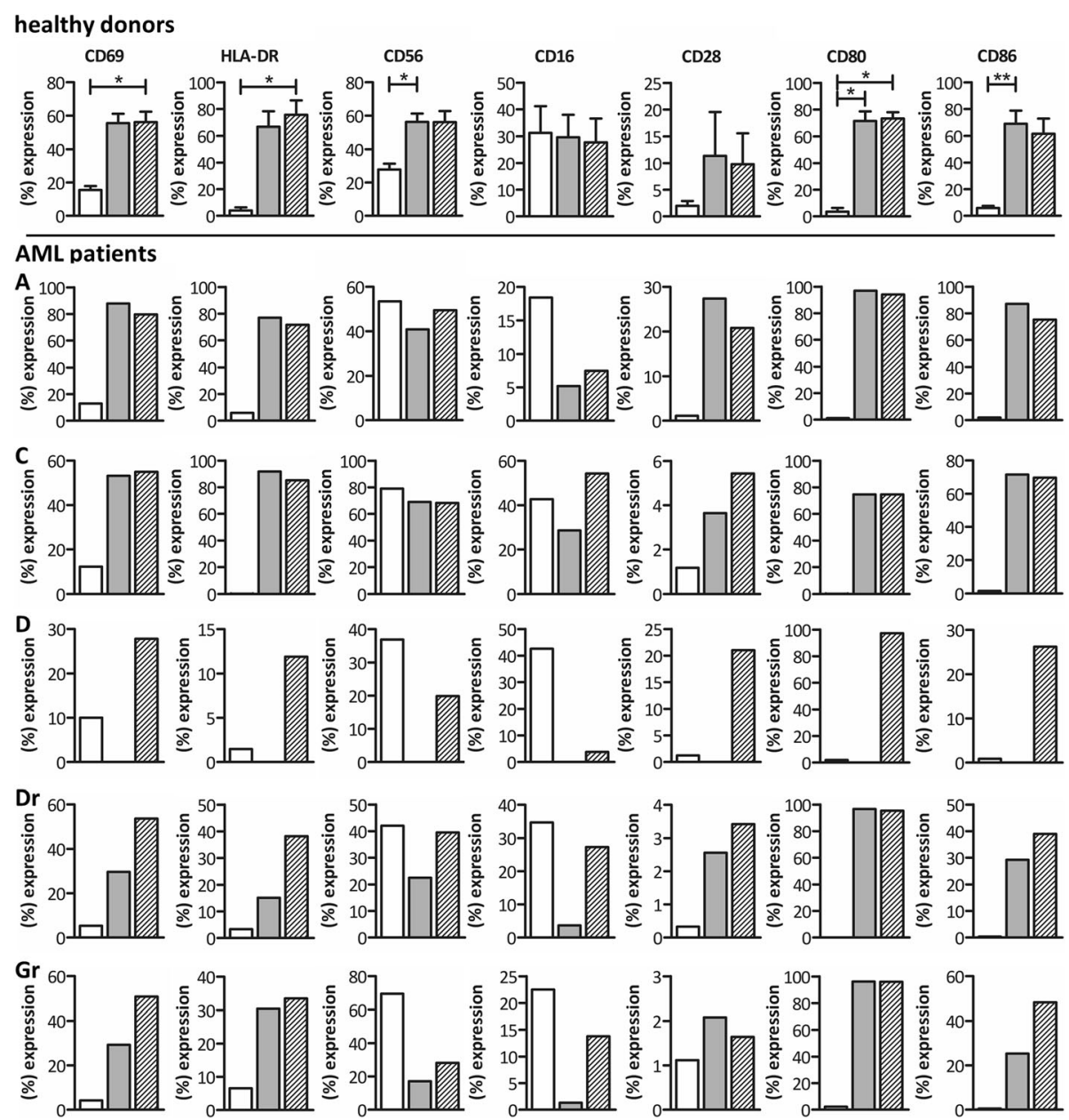

Fig. 5 Y $\delta$ T cell phenotype prior and subsequent to expansion. Comparison of the expression of CD69, HLA-DR, CD56, CD16, CD28, CD80, and CD86 on unstimulated (white bars), IL-2+zoledronate expanded (gray bars) and IL2+IL-15+zoledronate expanded (hatched bars) $\gamma \delta T$ cells. Results are shown for six healthy donors on the uppermost row as mean percentage. Expression levels of the respective markers of patient $\gamma \delta T$ cells are showed below. Due to the low number of $\gamma \delta T$ cells after expansion with IL-2 + zoledronaat of patient $\mathrm{D}$, no data are available. Friedman test with Dunn's multiple comparison test. ${ }^{* *} p<0.01 ;{ }^{*} p<0.05$

of IL-15-mediated activation was further validated in $\gamma \delta \mathrm{T}$ cells originating from AML patients.

A recent study in rhesus macaques showed that continuous administration of IL-15 is, among other, associated with increased numbers of circulating $\gamma \delta \mathrm{T}$ cells [39]. This has now been confirmed in the first-in-human trial of recombinant IL-15, whereby IL-15 administration in cancer patients induced both $\gamma \delta \mathrm{T}$ cell proliferation and activation [26]. These in vivo findings corroborate with our in vitro results, showing substantial proliferation of isolated $\gamma \delta \mathrm{T}$ cells upon stimulation with IL-15+IPP, but not with IL-2+IPP. In line herewith, Viey et al. demonstrated $\gamma \delta \mathrm{T}$ cell expansion out of tumor-infiltrating lymphocytes of renal cell carcinoma patients with bromohydrin pyrophosphate, a synthetic phosphoantigen, in combination with IL-15, while the combination with IL-2 was inefficient [5]. However, when we sought to extrapolate these results into a clinical 2-week expansion protocol based on IL-15 and zoledronate, inconsistencies in expansion successes were detected. In our hands, the best results were obtained when IL-15 and IL-2 were combined, suggesting that these cytokines have distinct roles in $\gamma \delta$ T cell biology. An advantage of IL-15 during expansion could be that IL-15 mediates homeostatic competition between $\alpha \beta$ T cells, NK cells and $\gamma \delta \mathrm{T}$ cells by a yet unknown indirect mechanism $[40,41]$. While we detect no difference in the final percentage of $\gamma \delta \mathrm{T}$ cells in expansion cultures of healthy donors with or without IL-15, this is certainly the case with the cultures of AML patients. In the IL-2+zoledronate cultures, we observed a higher proportion of other blood mononuclear cells, of which the vast majority were $\alpha \beta$ T cells. Addition of IL-15 may therefore have counteracted the growth of other cell types such as $\alpha \beta$ 


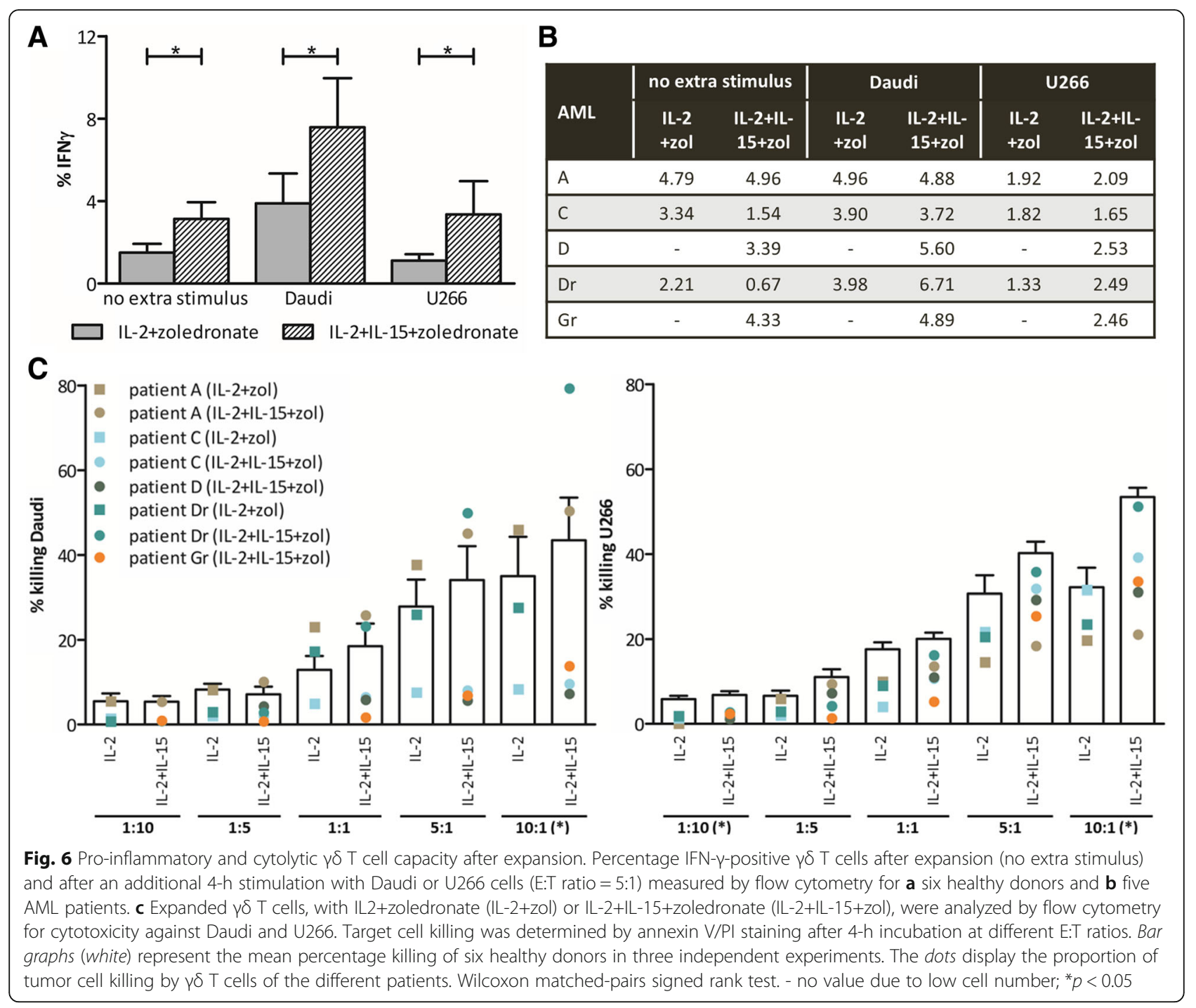

T cells, constraining the growth of the $\gamma \delta$ T cells, preventing cluster formation and subsequently successful $\gamma \delta \mathrm{T}$ cell expansion [40, 41]. It is possible that this process is more important when there is only a low percentage of $\gamma \delta$ T cells in the starting material or when $\gamma \delta$ $\mathrm{T}$ cells are less responsive, which is often the case in a malignant setting [42]. Moreover, $\gamma \delta$ T cells of AML patients generally exhibited a higher viability after expansion with IL-15, which was not observed with healthy donors. The question remains whether this improved viability is a result or the cause of the enhanced degree of $\gamma \delta$ T cell expansion. Nevertheless, it has been shown that IL-15 is very competent in supporting survival of activated $\gamma \delta$ T cells, superior to IL-2 [43], and T cell survival in general [44]. This does not mean that IL-2 is by definition redundant, as evidenced by our expansion results. The synergism between IL- 2 and IL-15 could lie in the fact that $\gamma \delta \mathrm{T}$ cells, in response to zoledronate and IL-2, upregulate their expression of inter alia IL$2 \mathrm{R} \beta$ and $\gamma_{\mathrm{c}}$ [43].

With regard to the effector/memory state of the $\gamma \delta \mathrm{T}$ cells after expansion, our results correspond with the available literature concerning $\gamma \delta \mathrm{T}$ cells expanded with IL-2 and zoledronate $[25,45]$. In particular, the majority of expanded $\gamma \delta$ T cells from healthy donors and patients showed for both expansion protocols a predominant effector memory type and, to a lesser extent, a central memory phenotype. Hence, the addition of IL-15 had no apparent influence on the effector/memory state. This is encouraging, since increased effector memory $\gamma \delta$ T cells are reported to correlate with objective clinical outcomes in patients treated with zoledronate and IL-2 [46]. On the other hand, adoptive transfer with $\alpha \beta \mathrm{T}$ cells has shown that it may also be important to preserve some less differentiated $\mathrm{T}$ cell subsets within the infused $\mathrm{T}$ cell product, to ensure $\mathrm{T}$ cell expansion and potentially long- 
term $\mathrm{T}$ cell persistence [47-49]. Given the presence of $\gamma \delta \mathrm{T}$ cells with a central memory phenotype upon expansion, our culture protocol fulfills the above-mentioned necessity. Moreover, contributing to the rationale of implementing IL-15 in expansion protocols, it has recently been shown that IL-15 instructs the generation of human memory stem $\mathrm{T}$ cells, a $\mathrm{T}$ cell subset with superior antitumor responses [50], from naive precursors $[49,51]$.

When looking in detail at the phenotype of cultured $\gamma \delta \mathrm{T}$ cells, two findings stand out from our results. First, incubation with IL-15+IPP led to a significant upregulation of CD56 relative to IL-2+IPP stimulated and unstimulated $\gamma \delta \mathrm{T}$ cells. In addition to the stringent association of CD56 with NK cells, CD56 has also been detected on other lymphoid cells, including $\gamma \delta \mathrm{T}$ cells and activated $\mathrm{CD} 8^{+} \mathrm{T}$ cells [52-55]. Moreover, CD56 in the human hematopoietic system is not restricted to lymphoid cells. Both $\mathrm{CD} 56^{+}$plasmacytoid dendritic cells (DCs) and myeloid DCs, including our IL-15 DCs, feature cytotoxic activity, in addition to serving classical DC functions [56]. In this context, it has been presumed that CD56 is associated with activated/cytotoxic effector immune cells [52, 54, 57-59]. This would implicate that IL-15 stimulation raises stronger cytotoxic $\gamma \delta$ T cells, as effectively confirmed by the enhanced killing of tumor cells in our experiments. Moreover, CD56 expression on $\gamma \delta \mathrm{T}$ cells following expansion was enhanced as well. Secondly, upon expansion, an increased expression of the co-stimulatory molecules CD80 and CD86 was observed. It has been shown that activated $\gamma \delta \mathrm{T}$ cells are able to acquire a professional antigen-presenting cell function, expressing high levels of co-stimulatory molecules [60]. This function may further boost the generation of a potent and long-lasting immune response.

In view of the functionality of $\gamma \delta \mathrm{T}$ cells, our experiments clearly show that IL-15, in comparison with IL-2, has a superior Th1 polarizing effect on $\gamma \delta$ T cells and markedly strengthens the $\gamma \delta \mathrm{T}$ cell cytotoxic capacity. These results are supported by in vivo data where intes-

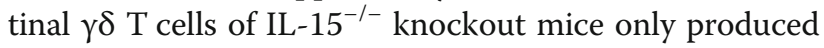
small amounts of IFN- $\gamma$ upon stimulation and showed significantly lower cytotoxicity against target cells as compared to wild-type mice [61]. This indicates that IL15-mediated signals are indeed indispensable for the development of potent antitumor functions. Furthermore, IL-15 has proved itself superior at maintaining effector functions of already expanded and activated $\gamma \delta \mathrm{T}$ cells, evidenced by a higher IFN- $\gamma$ production and CD107a expression after stimulation with zoledronate pre-treated Daudi cells [43]. In addition, within the context of neonatal immunity, it has been shown that expansion of cord blood $\gamma \delta$ T cells with alendronate and IL-15 gave rise to $\gamma \delta \mathrm{T}$ cells capable of strong protective immune responses [62]. Although the differences between the effects of IL-2 and IL-15 were subtle, higher expression of among other granzyme B and perforin was detected after activation with IL-15 [62]. All these data therefore point towards the fact that IL- 15 is a pivotal signal to generate more powerful effector $\gamma \delta$ T cells. This has recently been substantiated by Ribot et al., identifying the MAPK/ERK-mediated IL-2/IL-15 signaling as the major functional differentiation pathway of human $\gamma \delta$ T cells towards antitumor (cytotoxic type 1) effector cells [63].

\section{Conclusions}

Taken together, we have demonstrated that the addition of immunostimulatory cytokine IL-15 to in vitro $\gamma \delta \mathrm{T}$ cell cultures, derived from both AML patients and healthy blood donors, resulted in a more activated phenotype and significantly increased the antitumor functions of $\gamma \delta$ T cells. This was manifested in a higher yield of expanded $\gamma \delta$ T cells, a more pronounced Th1 polarization and an increased cytotoxic capacity, all desirable characteristics for their further use in adoptive immunotherapy. Therefore, our results strengthen the rationale to explore the use of IL-15 in clinical adoptive therapy protocols.

\begin{abstract}
Abbreviations
AML: Acute myeloid leukemia; CFSE: 5,6-carboxyfluorescein diacetate succinimidyl ester; DC: Dendritic cell; E:T: Effector-to-target; FBS: Fetal bovine serum; HSCT: Hematopoietic stem cell transplantation; IFN: Interferon; IL: Interleukin; IMDM: Iscove's Modified Dulbecco's Medium; IPP: Isopentenyl pyrophosphate; NK: Natural killer; PBMC: Peripheral blood mononuclear cells; PI: Propidium iodide; RPMI: Roswell Park Memorial Institute; TCR: T cell receptor; Th: T helper; TNF: Tumor necrosis factor
\end{abstract}

\section{Acknowledgements}

Not applicable.

\section{Funding}

This work was supported by grant G.0399.14 from the Fund for Scientific Research Flanders (FWO Vlaanderen) and by a Methusalem grant from the University of Antwerp (attributed to prof. H. Goossens). Part of this work was performed under the umbrella of the European COST TD1104 action (EP4Bio2MED; http://www.cost.eu/COST_Actions/bmbs/TD1104). HHVA is a former PhD fellow of the Agency for Innovation by Science and Technology (IWT, Belgium) and is currently supported by a PhD grant of the FWO,

JMVDB holds a fellowship from the Faculty of Medicine and Health Sciences of the University of Antwerp, SA is a former holder of an Emmanuel van der Schueren Fellowship granted by the Flemish League against Cancer, and YW is a former PhD fellow of the IWT.

\section{Availability of data and materials \\ The datasets during and/or analyzed during the current study are available from the corresponding author on reasonable request.}

\section{Authors' contributions}

HHVA, SA, ZNB, EL, ELS, and VFVT conceived and designed the experiments. HHVA, SA, YW, and JMVDB performed the experiments. HHVA analyzed the data. HHVA, ELS, and VFVT wrote the paper. All authors have read and approved the manuscript in its current form.

\section{Competing interests}

The authors declare that they have no competing interests.

Consent for publication

Not applicable. 


\section{Ethics approval}

This study was approved by the Ethics Committee of the Antwerp University Hospital (Edegem, Belgium) under the reference number B300201419756.

\begin{abstract}
Author details
'Laboratory of Experimental Hematology, Tumor Immunology Group (TIGR), Vaccine and Infectious Disease Institute (VAXINFECTIO), Faculty of Medicine and Health Sciences, University of Antwerp, Wilrijkstraat 10, 2650 Edegem, Antwerp, Belgium. ${ }^{2}$ Center for Cell Therapy and Regenerative Medicine, Antwerp University Hospital, Wilrijkstraat 10, 2650 Edegem, Belgium. ${ }^{3}$ Center for Oncological Research (CORE), Faculty of Medicine and Health Sciences, University of Antwerp, Universiteitsplein 1, 2610 Wilrijk, Antwerp, Belgium.
\end{abstract}

\section{Received: 10 August 2016 Accepted: 16 September 2016} Published online: 29 September 2016

\section{References}

1. Van Acker HH, Anguille S, Van Tendeloo VF, Lion E. Empowering gamma delta $T$ cells with antitumor immunity by dendritic cell-based immunotherapy. Oncoimmunology. 2015;4:e1021538.

2. Girardi M, Oppenheim DE, Steele CR, et al. Regulation of cutaneous malignancy by gammadelta T cells. Science. 2001;294:605-9.

3. He W, Hao J, Dong S, et al. Naturally activated $V$ gamma 4 gamma delta $T$ cells play a protective role in tumor immunity through expression of eomesodermin. J Immunol. 2010;185:126-33.

4. Aswald JM, Wang XH, Aswald S, et al. Flow cytometric assessment of autologous gammadelta $T$ cells in patients with acute myeloid leukemia: potential effector cells for immunotherapy? Cytometry B Clin Cytom. 2006;70:379-90

5. Viey $E_{\text {, Lucas }} \mathrm{C}$, Romagne $\mathrm{F}$, et al. Chemokine receptors expression and migration potential of tumor-infiltrating and peripheral-expanded Vgamma9Vdelta2 T cells from renal cell carcinoma patients. J Immunother 2008;31:313-23.

6. Gentles AJ, Newman AM, Liu CL, et al. The prognostic landscape of genes and infiltrating immune cells across human cancers. Nat Med. 2015;21:938-45

7. Deniger DC, Moyes JS, Cooper LJ. Clinical applications of gamma delta T cells with multivalent immunity. Front Immunol. 2014;5:636.

8. Legut M, Cole DK, Sewell AK. The promise of gammadelta T cells and the gammadelta T cell receptor for cancer immunotherapy. Cell Mol Immunol. 2015;12:656-68.

9. Kantarjian $\mathrm{H}$. Acute myeloid leukemia-major progress over four decades and glimpses into the future. Am J Hematol. 2016;91:131-45.

10. Walter RB, Estey EH. Management of older or unfit patients with acute myeloid leukemia. Leukemia. 2015;29:770-5.

11. Grosso DA, Hess RC, Weiss MA. Immunotherapy in acute myeloid leukemia. Cancer. 2015;121:2689-704.

12. Minculescu $L$, Sengelov $H$. The role of gamma delta $T$ cells in haematopoietic stem cell transplantation. Scand J Immunol. 2015:81:459-68

13. Perko R, Kang G, Sunkara A, et al. Gamma delta T cell reconstitution is associated with fewer infections and improved event-free survival after hematopoietic stem cell transplantation for pediatric leukemia. Biol Blood Marrow Transplant. 2015;21:130-6.

14. Godder KT, Henslee-Downey PJ, Mehta J, et al. Long term disease-free survival in acute leukemia patients recovering with increased gammadelta $T$ cells after partially mismatched related donor bone marrow transplantation. Bone Marrow Transplant. 2007;39:751-7.

15. Dohner H, Estey EH, Amadori S, et al. Diagnosis and management of acute myeloid leukemia in adults: recommendations from an international expert panel, on behalf of the European LeukemiaNet. Blood. 2010;115:453-74.

16. Buccheri S, Guggino G, Caccamo N, et al. Efficacy and safety of gammadeltaT cell-based tumor immunotherapy: a meta-analysis. J Biol Regul Homeost Agents. 2014;28:81-90.

17. Airoldi I, Bertaina A, Prigione I, et al. Gammadelta T-cell reconstitution after HLA-haploidentical hematopoietic transplantation depleted of TCR-alphabeta+/CD19+ lymphocytes. Blood. 2015;125:2349-58.

18. Bhat J, Kabelitz D. Gammadelta T cells and epigenetic drugs: a useful merger in cancer immunotherapy? Oncoimmunology. 2015;4:e1006088.
19. Fisher JP, Heuijerjans J, Yan M, et al. Gammadelta T cells for cancer immunotherapy: a systematic review of clinical trials. Oncoimmunology. 2014;3:e27572

20. Sharma P, Allison JP. Immune checkpoint targeting in cancer therapy: toward combination strategies with curative potential. Cell. 2015:161:205-14.

21. Silva-Santos B, Serre K, Norell H. Gammadelta T cells in cancer. Nat Rev Immunol. 2015;15:683-91.

22. Van Acker HH, Anguille S, Willemen Y, et al. Bisphosphonates for cancer treatment: mechanisms of action and lessons from clinical trials. Pharmacol Ther. 2016;158:24-40.

23. Correia DV, Lopes A, Silva-Santos B. Tumor cell recognition by gammadelta T lymphocytes: T-cell receptor vs. NK-cell receptors. Oncoimmunology. 2013;2:e22892.

24. Roelofs AJ, Jauhiainen $\mathrm{M}$, Monkkonen $\mathrm{H}$, et al. Peripheral blood monocytes are responsible for gammadelta $T$ cell activation induced by zoledronic acid through accumulation of IPP/DMAPP. Br J Haematol. 2009:144:245-50.

25. Nicol AJ, Tokuyama H, Mattarollo SR, et al. Clinical evaluation of autologous gamma delta T cell-based immunotherapy for metastatic solid tumours. Br J Cancer. 2011;105:778-86.

26. Conlon KC, Lugli E, Welles HC, et al. Redistribution, hyperproliferation, activation of natural killer cells and CD8 T cells, and cytokine production during first-in-human clinical trial of recombinant human interleukin-15 in patients with cancer. J Clin Oncol. 2015;33:74-82.

27. Cheever MA. Twelve immunotherapy drugs that could cure cancers. Immunol Rev. 2008:222:357-68.

28. Ring AM, Lin JX, Feng $D$, et al. Mechanistic and structural insight into the functional dichotomy between IL-2 and IL-15. Nat Immunol. 2012;13:1187-95.

29. Waldmann TA. The biology of interleukin-2 and interleukin-15: implications for cancer therapy and vaccine design. Nat Rev Immunol. 2006;6:595-601.

30. Van den Bergh JM, Van Tendeloo VF, Smits EL. Interleukin-15: new kid on the block for antitumor combination therapy. Cytokine Growth Factor Rev. 2014:26:15-24

31. Morris JC, Ramlogan-Steel CA, Yu P, et al. Vaccination with tumor cells expressing IL-15 and IL-15Ralpha inhibits murine breast and prostate cancer. Gene Ther. 2014;21:393-401.

32. Teague RM, Sather BD, Sacks JA, et al. Interleukin-15 rescues tolerant CD8+ T cells for use in adoptive immunotherapy of established tumors. Nat Med. 2006;12:335-41.

33. Bennouna J, Bompas E, Neidhardt EM, et al. Phase-I study of Innacell gammadelta, an autologous cell-therapy product highly enriched in gamma9delta2 T lymphocytes, in combination with IL-2, in patients with metastatic renal cell carcinoma. Cancer Immunol Immunother. 2008:57:1599-609.

34. Salot S, Bercegeay S, Dreno B, et al. Large scale expansion of Vgamma9Vdelta2 T lymphocytes from human peripheral blood mononuclear cells after a positive selection using MACS "TCR gamma/delta + T cell isolation kit". J Immunol Methods. 2009;347:12-8.

35. Rosenberg SA, Lotze MT, Muul LM, et al. Observations on the systemic administration of autologous lymphokine-activated killer cells and recombinant interleukin-2 to patients with metastatic cancer. N Engl J Med. 1985:313:1485-92.

36. Oliveira G, Ruggiero E, Stanghellini MT, et al. Tracking genetically engineered lymphocytes long-term reveals the dynamics of $T$ cell immunological memory. Sci Transl Med. 2015;7:317ra198.

37. Yee $\mathrm{C}$. The use of endogenous T cells for adoptive transfer. Immunol Rev. 2014;257:250-63.

38. Turtle CJ, Hanafi LA, Berger C et al. CD19 CAR-T cells of defined CD4+:CD8+ composition in adult B cell ALL patients. J Clin Invest. 2016;126:2123-138.

39. Sneller MC, Kopp WC, Engelke KJ, et al. IL-15 administered by continuous infusion to rhesus macaques induces massive expansion of CD8+ T effector memory population in peripheral blood. Blood. 2011;118:6845-8.

40. Do JS, Min B. IL-15 produced and trans-presented by DCs underlies homeostatic competition between CD8 and \{gamma\}\{delta\} T cells in vivo. Blood. 2009:113:6361-71.

41. French JD, Roark CL, Born WK, O'Brien RL. \{gamma\}\{delta\} T cell homeostasis is established in competition with \{alpha\}\{beta\} T cells and NK cells. Proc Natl Acad Sci U S A. 2005;102:14741-6.

42. Capietto AH, Martinet L, Fournie JJ. How tumors might withstand gammadelta T-cell attack. Cell Mol Life Sci. 2011;68:2433-42. 
43. Izumi $\mathrm{T}$, Kondo M, Takahashi $\mathrm{T}$, et al. Ex vivo characterization of gammadelta T-cell repertoire in patients after adoptive transfer of Vgamma9Vdelta2 T cells expressing the interleukin-2 receptor beta-chain and the common gamma-chain. Cytotherapy. 2013;15:481-91.

44. Steel JC, Waldmann TA, Morris JC. Interleukin-15 biology and its therapeutic implications in cancer. Trends Pharmacol Sci. 2012;33:35-41.

45. Nakajima J, Murakawa T, Fukami T, et al. A phase I study of adoptive immunotherapy for recurrent non-small-cell lung cancer patients with autologous gammadelta T cells. Eur J Cardiothorac Surg. 2010;37:1191-7.

46. Dieli F, Vermijlen D, Fulfaro F, et al. Targeting human \{gamma\}delta\} T cells with zoledronate and interleukin-2 for immunotherapy of hormone-refractory prostate cancer. Cancer Res. 2007;67:7450-7.

47. Powell Jr DJ, Dudley ME, Robbins PF, Rosenberg SA. Transition of late-stage effector T cells to CD27+ CD28+ tumor-reactive effector memory T cells in humans after adoptive cell transfer therapy. Blood. 2005;105:241-50.

48. Klebanoff CA, Scott CD, Leonardi AJ, et al. Memory T cell-driven differentiation of naive cells impairs adoptive immunotherapy. J Clin Invest. 2016;126:318-34

49. Xu Y, Zhang M, Ramos CA, et al. Closely related T-memory stem cells correlate with in vivo expansion of CAR.CD19-T cells and are preserved by IL-7 and IL-15. Blood. 2014;123:3750-9.

50. Gattinoni L, Lugli E, Ji Y, et al. A human memory T cell subset with stem cell-like properties. Nat Med. 2011;17:1290-7.

51. Cieri N, Camisa B, Cocchiarella F, et al. IL-7 and IL-15 instruct the generation of human memory stem T cells from naive precursors. Blood. 2013;121:573-84.

52. Alexander AA, Maniar A, Cummings JS, et al. Isopentenyl pyrophosphate-activated CD56+ \{gamma\}\{delta\} T lymphocytes display potent antitumor activity toward human squamous cell carcinoma. Clin Cancer Res. 2008;14:4232-40.

53. Kelly-Rogers J, Madrigal-Estebas L, O'Connor T, Doherty DG. Activation-induced expression of CD56 by T cells is associated with a reprogramming of cytolytic activity and cytokine secretion profile in vitro. Hum Immunol. 2006;67:863-73.

54. Valgardsdottir R, Capitanio C, Texido G, et al. Direct involvement of CD56 in cytokine-induced killer-mediated lysis of CD56+ hematopoietic target cells. Exp Hematol. 2014;42:1013-21. e1011.

55. Wagner S, Wittekindt C, Reuschenbach M et al. CD56-positive lymphocyte infiltration in relation to human papillomavirus association and prognostic significance in oropharyngeal squamous cell carcinoma. Int J Cancer. 2015; 138:2263-73.

56. Roothans D, Smits E, Lion E, et al. CD56 marks human dendritic cell subsets with cytotoxic potential. Oncoimmunology. 2013;2:e23037.

57. Gruenbacher G, Nussbaumer O, Gander H, et al. Stress-related and homeostatic cytokines regulate Vgamma9Vdelta2 T-cell surveillance of mevalonate metabolism. Oncoimmunology. 2014;3:e953410.

58. Tel J, Smits EL, Anguille S, et al. Human plasmacytoid dendritic cells are equipped with antigen-presenting and tumoricidal capacities. Blood. 2012;120:3936-44.

59. Anguille S, Lion E, Tel J, et al. Interleukin-15-induced CD56(+) myeloid dendritic cells combine potent tumor antigen presentation with direct tumoricidal potential. PLoS One. 2012;7:e51851.

60. Moser B, Eberl M. gammadelta T-APCs: a novel tool for immunotherapy? Cell Mol Life Sci. 2011;68:2443-52.

61. Nakazato K, Yamada H, Yajima T, et al. Enforced expression of Bcl-2 partially restores cell numbers but not functions of TCRgammadelta intestinal intraepithelial T lymphocytes in IL-15-deficient mice. J Immunol. 2007;178:757-64.

62. Cairo C, Sagnia B, Cappelli G, et al. Human cord blood gammadelta T cells expressing public Vgamma2 chains dominate the response to bisphosphonate plus interleukin-15. Immunology. 2013;138:346-60.

63. Ribot JC, Ribeiro ST, Correia DV, et al. Human gammadelta thymocytes are functionally immature and differentiate into cytotoxic type 1 effector T cells upon IL-2/IL-15 signaling. J Immunol. 2014;192:2237-43.

\section{Submit your next manuscript to BioMed Central and we will help you at every step:}

- We accept pre-submission inquiries

- Our selector tool helps you to find the most relevant journal

- We provide round the clock customer support

- Convenient online submission

- Thorough peer review

- Inclusion in PubMed and all major indexing services

- Maximum visibility for your research

Submit your manuscript at www.biomedcentral.com/submit
Biomed Central 